\title{
Cathodoluminescence of Nanocrystalline $\mathrm{Y}_{2} \mathrm{O}_{3}: \mathrm{Eu}^{3+}$ with Various $\mathrm{Eu}^{3+}$ Concentrations
}

\author{
Daniel den Engelsen, Paul Harris, Terry Ireland, ${ }^{\mathbf{Z}}$ and Jack Silver ${ }^{\mathbf{Z}}$ \\ Centre for Phosphor and Display Materials, Wolfson Centre for Materials Processing, Brunel University London, \\ Kingston Lane, Uxbridge, Middlesex, UB8 3PH, United Kingdom
}

\begin{abstract}
Herein a study on the preparation and cathodoluminescence of monosized spherical nanoparticles of Y2O3:Eu3+ having a Eu3+ concentration that varies between 0.01 and $10 \%$ is described. The luminous efficiency and decay time have been determined at low a current density, whereas cathodoluminescence-microscopy has been carried out at high current density, the latter led to substantial saturation of certain spectral transitions. A novel theory is presented to evaluate the critical distance for energy transfer from Eu3+ ions in S6 to Eu3+ ions in C2 sites. It was found that $\mathrm{Y} 2 \mathrm{O} 3: \mathrm{Eu} 3+$ with 1-2\% Eu3+ has the highest luminous efficiency of $16 \mathrm{~lm} / \mathrm{w}$ at $15 \mathrm{keV}$ electron energy. Decay times of the emission from 5D0 (C2) and 5D1 (C2) and 5D0 (S6) levels were determined. The difference in decay time from the 5D0 (C2) and 5D1 (C2) levels largely explained the observed phenomena in the cathodoluminescence-micrographs recorded with our field emission scanning electron microscope.

(c) The Author(s) 2014. Published by ECS. This is an open access article distributed under the terms of the Creative Commons Attribution 4.0 License (CC BY, http://creativecommons.org/licenses/by/4.0/), which permits unrestricted reuse of the work in any medium, provided the original work is properly cited. [DOI: 10.1149/2.0141412jss] All rights reserved.
\end{abstract}

Manuscript submitted September 17, 2014; revised manuscript received October 16, 2014. Published November 3, 2014.

In a study of the cathodoluminescence (CL) of europium-doped yttrium oxide $\left(\mathrm{Y}_{2} \mathrm{O}_{3}: \mathrm{Eu}^{3+}\right)$ and zinc-doped zinc oxide ( $\left.\mathrm{ZnO}: \mathrm{Zn}\right)$ we described both a new measuring method ${ }^{1}$ and an idea to maximize the light output of single and multilayers of particles of these phosphors. ${ }^{2}$ The phosphors used in these published studies were spherical nanoparticles of $\mathrm{Y}_{2} \mathrm{O}_{3}: \mathrm{Eu}^{3+}$ and micrometer sized $\mathrm{ZnO}: \mathrm{Zn}$ particles. The spherical nanoparticles of $\mathrm{Y}_{2} \mathrm{O}_{3}: \mathrm{Eu}^{3+}$ were not monodisperse, because they consisted of a mixture of various batches. The objective of the continuation of our investigations that are reported herein was preparing and characterizing monosized spherical nanoparticles of $\mathrm{Y}_{2} \mathrm{O}_{3}: \mathrm{Eu}^{3+}$ with various concentrations of $\mathrm{Eu}^{3+}$. In this work CLtechniques were used as the characterization method of choice: in a vacuum system equipped with an electron gun and spectrometers, and in a field emission scanning electron microscope (FESEM). ${ }^{3}$

The application of $\mathrm{Y}_{2} \mathrm{O}_{3}: \mathrm{Eu}^{3+}$ in cathode ray tubes has fostered extended luminescence studies of this material. Before 1996 these studies were focused mainly on micrometer sized particles, ${ }^{4-12}$ more recently the attention has been directed to nano-sized powder materials. ${ }^{13-19}$ In the earlier studies ${ }^{4-12}$ the focus was on the interpretation of the excitation and emission spectra in terms of energy transfer in the $\mathrm{Y}_{2} \mathrm{O}_{3}: \mathrm{Eu}^{3+}$ crystals, whereas in the latter studies ${ }^{13-19}$ the attention shifted toward the synthesis of nanomaterials. Most studies used photoluminescence (PL) techniques, ${ }^{4-7}$ which enabled the excitation of energy levels having a particular symmetry and yielded insight on the energy flow in $\mathrm{Y}_{2} \mathrm{O}_{3}: \mathrm{Eu}^{3+}$. Most studies on the CL of $\mathrm{Y}_{2} \mathrm{O}_{3}: \mathrm{Eu}^{3+}$ were limited to the evaluation of the luminous efficiency. ${ }^{10-12}$

A detailed investigation of the energy flow in $\mathrm{Y}_{2} \mathrm{O}_{3}: \mathrm{Eu}^{3+}$ after excitation by an electron beam was performed by Klaassen et al. ${ }^{8}$ These authors also studied saturation effects in $\mathrm{Y}_{2} \mathrm{O}_{3}: \mathrm{Eu}^{3+}$ at high current densities in an electron microscope. ${ }^{9}$ Although the work of Klaassen et al. is comprehensive and extensive, it was considered worthwhile to investigate the CL-spectra at low current density and the decay behavior of $\mathrm{Y}_{2} \mathrm{O}_{3}: \mathrm{Eu}^{3+}$ at low and high current densities using a different method of analysis. Moreover, Klaassen et al. did not indicate which spectral transitions they selected for their analyses. This selection is not trivial, because many peaks in the spectrum of $\mathrm{Y}_{2} \mathrm{O}_{3}: \mathrm{Eu}^{3+}$ suffer from overlap or are combinations of more than one spectral transition. ${ }^{5,6}$

The first phase in the energy flow in $\mathrm{Y}_{2} \mathrm{O}_{3}: \mathrm{Eu}^{3+}$ after excitation of the $\mathrm{Y}_{2} \mathrm{O}_{3}$ lattice by an electron beam is charge transfer by exciting the $\mathrm{Eu}^{3+}$ ions. Then fast radiationless relaxation to the various ${ }^{5} \mathrm{D}_{\mathrm{J}}$ levels of $\mathrm{Eu}^{3+}$ takes place. From these levels light is emitted. How the various ${ }^{5} \mathrm{D}_{\mathrm{J}}$ levels are populated will not be addressed, but rather

zE-mail: jack.silver@brunel.ac.uk; terry.ireland@brunel.ac.uk limit the study to the energy transfer between $\mathrm{Eu}^{3+}$ ions in the two crystallographic sites. Pure and $\mathrm{Eu}^{3+}$ doped $\mathrm{Y}_{2} \mathrm{O}_{3}$ crystals have the cubic structure of the mineral bixbyite with $16 \mathrm{Y}_{2} \mathrm{O}_{3}$ molecules in one cell. ${ }^{4,20}$ In $\mathrm{Y}_{2} \mathrm{O}_{3}$ there are two different $\mathrm{Y}^{3+}$ lattice sites, which possess the point symmetries $C_{2}$ and $S_{6}$ (Schoenflies notation): 24 lattice sites have $\mathrm{C}_{2}$ symmetry, while the other 8 have $\mathrm{S}_{6}$ symmetry. Both sites are six coordinate and are thus present in the ratio of 3:1. The sites are presented in Figure 1. Upon doping $\mathrm{Y}_{2} \mathrm{O}_{3}$ with $\mathrm{Eu}^{3+}$ these lattice sites are occupied with $\mathrm{Eu}^{3+}$ with almost equal probability. ${ }^{4}$

Heber et al. ${ }^{4}$ and Buijs et al. ${ }^{7}$ derived from PL-measurements of $\mathrm{Y}_{2} \mathrm{O}_{3}: \mathrm{Eu}^{3+}$ with various $\mathrm{Eu}^{3+}$ concentrations and at various temperatures respectively that after excitation of a crystal with high $\mathrm{Eu}^{3+}$ concentration, energy can be transferred from $\mathrm{S}_{6}$ states to $\mathrm{C}_{2}$ states. At low $\mathrm{Eu}^{3+}$ concentration there is no interaction between $\mathrm{E} \mathrm{Eu}^{3+}$ ion at $\mathrm{S}_{6}$ site and $\mathrm{Eu}^{3+}$ ion at a $\mathrm{C}_{2}$ site respectively and thus, there will be no energy transfer. Energy transfer also occurs in phosphors that are excited by an electron beam; therefore, it was also an objective of this work to investigate what information concerning energy transfer can be obtained from CL-spectra that are generated without activation of specified energy levels.

In a review entitled "Probes of Structural and Electronic Environments of Phosphor Activators: Mossbauer and Raman Spectroscopy" we commented on work reported on commercial $\mathrm{Y}_{2} \mathrm{O}_{3}: \mathrm{Eu}^{3+}$ phosphors. ${ }^{21}$ This work showed that in $\mathrm{Y}_{2} \mathrm{O}_{3}: \mathrm{Eu}^{3+}$, having an $\mathrm{Eu}^{3+}$ concentration of ca. 4.7 mole \%, efficient energy transfer occurs between the $S_{6}$ and $C_{2}$ sites for $E^{3+}$ in the ${ }^{5} D_{0}$ level. As the ${ }^{5} D_{0}$ level in the $S_{6}$ site is $87 \mathrm{~cm}^{-1}$ higher than the same level in the $C_{2}$ site, the efficient energy transfer from $S_{6}$ to $C_{2}$ sites presumably occurs by simultaneous creation of a phonon. ${ }^{22}$ This efficient energy transfer is necessary for the high emission efficiency of the $\mathrm{Y}_{2} \mathrm{O}_{3}: \mathrm{Eu}^{3+}$ phosphor, as the ${ }^{5} \mathrm{D}_{0} \rightarrow{ }^{7} \mathrm{~F}_{2}$ transition which gives rise to the red $611 \mathrm{~nm}$ emission is electric dipole allowed for $\mathrm{Eu}^{3+}$ in $\mathrm{C}_{2}$ sites but forbidden for $\mathrm{Eu}^{3+}$ in $\mathrm{S}_{6}$ sites.

In this work it was decided to focus on the ${ }^{5} \mathrm{D}_{0} \rightarrow{ }^{7} \mathrm{~F}_{1}\left(\mathrm{~S}_{6}\right)$ transition at $582 \mathrm{~nm}$ and the ${ }^{5} \mathrm{D}_{0} \rightarrow{ }^{7} \mathrm{~F}_{2}\left(\mathrm{C}_{2}\right)$ transition at $611 \mathrm{~nm}$, because these are reasonably well separated from other transitions ${ }^{6}$ and allow luminescence decay measurements that are not perturbed by a large overlap of nearby transitions. Another important condition for this selection was the radiance of the ${ }^{5} \mathrm{D}_{0} \rightarrow{ }^{7} \mathrm{~F}_{1}\left(\mathrm{~S}_{6}\right)$ transition at $582 \mathrm{~nm}$, which was sufficient to perform decay measurements at room temperature.

The outline of this paper is as follows. In the experimental section the synthesis of monosized spherical $\mathrm{Y}_{2} \mathrm{O}_{3}: \mathrm{Eu}^{3+}$ nanoparticles, the deposition of thin films and the measuring methods are described. Results and discussions thereof are presented in the subsequent section. The final section contains the conclusions. 


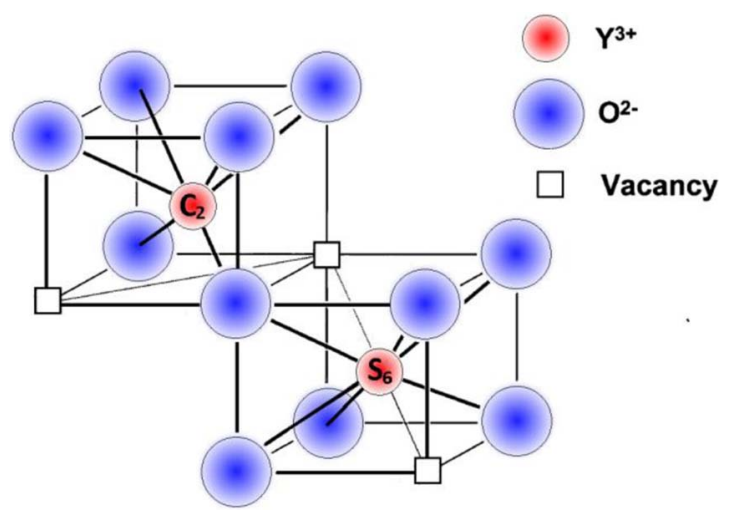

Figure 1. $\mathrm{C}_{2}$ and $\mathrm{S}_{6}$ sites of the $\mathrm{Y}^{3+}$ cation in cubic $\mathrm{Y}_{2} \mathrm{O}_{3}$. These sites have vacancies on a face diagonal and a body diagonal, respectively.

\section{Experimental}

Materials. - Yttrium oxide $(99.99 \%)$ and europium oxide (99.99\%) were obtained from Ampere Industrie, France; urea, nitric acid and isopropanol (IPA) were supplied by Fisher Scientific, UK., all chemicals were used as received. Glass substrates $\left(1 \mathrm{~cm}^{2}\right)$ coated with an indium tin oxide (ITO) film $(85 \Omega / \mathrm{sq})$ were obtained from Visiontek Ltd., UK. Aluminum pin stubs for the FESEM studies were polished before cleaning. The ITO and aluminum pin stubs were carefully cleaned in de-ionised water and IPA using ultrasonic cavitation. Conductive carbon tabs coated with adhesive on both sides were also used for the attaching samples for FESEM imaging studies.

Synthesis of monosized spherical $\mathrm{Y}_{2} \mathrm{O}_{3}: \mathrm{Eu}^{3+}$ nanoparticles.- The synthesis of monosized spherical $\mathrm{Y}_{2} \mathrm{O}_{3}: \mathrm{Eu}^{3+}$ nanoparticles by the urea method has been described extensively in our earlier work. ${ }^{1,13,23}$ Since the aim was synthesizing particles with a diameter of about $225 \mathrm{~nm}$ after annealing at high temperature, the aging of the turbid suspensions for all samples was continued for one hour at $90^{\circ} \mathrm{C}$. This aging time essentially determined the diameter of the spherical particles.

Sample preparation.- Thin films of monosized spherical $\mathrm{Y}_{2} \mathrm{O}_{3}: \mathrm{Eu}^{3+}$ nanoparticles $\left(2 \mathrm{mg} / \mathrm{cm}^{2}\right)$ were deposited onto ITOsubstrates by electrophoresis from an IPA suspension for the luminance studies. Previously we have reported ${ }^{1}$ that deposition of $\mathrm{Y}_{2} \mathrm{O}_{3}: \mathrm{Eu}^{3+}$ by electrophoresis from an IPA-suspension to which $37.5 \mathrm{mg} \mathrm{Mg}\left(\mathrm{NO}_{3}\right)_{2}$ (for $500 \mathrm{ml}$ IPA) was added to induce charging of the $\mathrm{Y}_{2} \mathrm{O}_{3}: \mathrm{Eu}^{3+}$ particles which led to layers that were nonuniformly coated and therefore produced considerable light scattering. Although the addition of $\mathrm{Mg}\left(\mathrm{NO}_{3}\right)_{2}$ is generally recommended for electrophoretic deposition of phosphor particles onto conductive substrates, ${ }^{24}$ by omitting $\mathrm{Mg}\left(\mathrm{NO}_{3}\right)_{2}$ it was possible to deposit uniform layers that had no excessive light scattering. Thus, it may be concluded that by not adding $\mathrm{Mg}\left(\mathrm{NO}_{3}\right)_{2}$ the Debye layer surrounding the nanoparticles was large enough to prevent agglomeration of the particles, while the charging of the particles was sufficient to enable an acceptable coating time of about 2 minutes.

Measuring methods. - The morphology and particle size assessment of the phosphor powders were undertaken using a FESEM, Supra 35 VP, Carl Zeiss, Germany.

The microscope is equipped with four detector systems as shown in Figure 2. The first is an Everhart-Thornley (ET) SE detector, which collects primarily secondary electrons (SEs), although some backscattered electrons (BSEs) may also contribute.

There is also an in-lens SE detector, for use when a very short working distance is required, and this detects only SEs. An annular (retractable) Robinson solid state BSE detector is mounted immediately above the sample. The microscope has also a facility to collect CL generated by the electron beam when it hits a phosphor. After amplification of these light signals in a photomultiplier high quality panchromatic CL-images of phosphor materials can be obtained. We have used this facility to study the decay behavior of $\mathrm{Y}_{2} \mathrm{O}_{3}: \mathrm{Eu}^{3+}$. Image analysis of the panchromatic CL-micrographs was performed using ImageJ (Public Domain) software.CL micrographs are represented in shades of grey; they are therefore called panchromatic. The gray shade $G(i, j)$ in a $C L$ graph, where $i$ and $j$ indicate a pixel in the $\mathrm{i}^{\text {th }}$ row and $\mathrm{j}^{\text {th }}$ column, can be written as:

$$
G(i, j)=V(i, j) \int_{\lambda 1}^{\lambda 2} P(i, j) s(\lambda) d \lambda
$$

where $\mathrm{V}(\mathrm{i}, \mathrm{j})$ is a geometrical factor representing the viewing factor of the pixel $i, j$ to the optical detector. From this definition it follows that $\mathrm{V}(\mathrm{i}, \mathrm{j})$ also takes care of shadowing effects caused by other particles. $P(i, j)$ is the power spectrum of the material at pixel $i, j$ and $s(\lambda)$ is the sensitivity of the photocathode of the photomultiplier. The integration is made between the minimum and maximum wavelengths of $s(\lambda)$. From Eq. 1 it is immediately clear that the greyscale in a CLmicrograph is not equal to the radiance, since $\mathrm{P}(\mathrm{i}, \mathrm{j})$ is convoluted with s. The term $G(i, j)$ is also a function of time, because of decay of the fluorescence (or phosphorescence). If the decay time is more than 4 orders of magnitude smaller than the scan rate (in frame/s), there will no smearing effect visible in the CL-micrograph. For longer decay times, smearing will be visible. The Zeiss Supra FESEM is provided with scan rates of $1.7 \mathrm{~s}(\mathrm{ss} 12)$ to $0.12 \mathrm{~ms}$ (ss1) per line and this defines the range of materials that can be studied. For weakly luminescent materials and/or the highest scan speeds the images can be repeatedly scanned and averaged to improve the signal to noise.

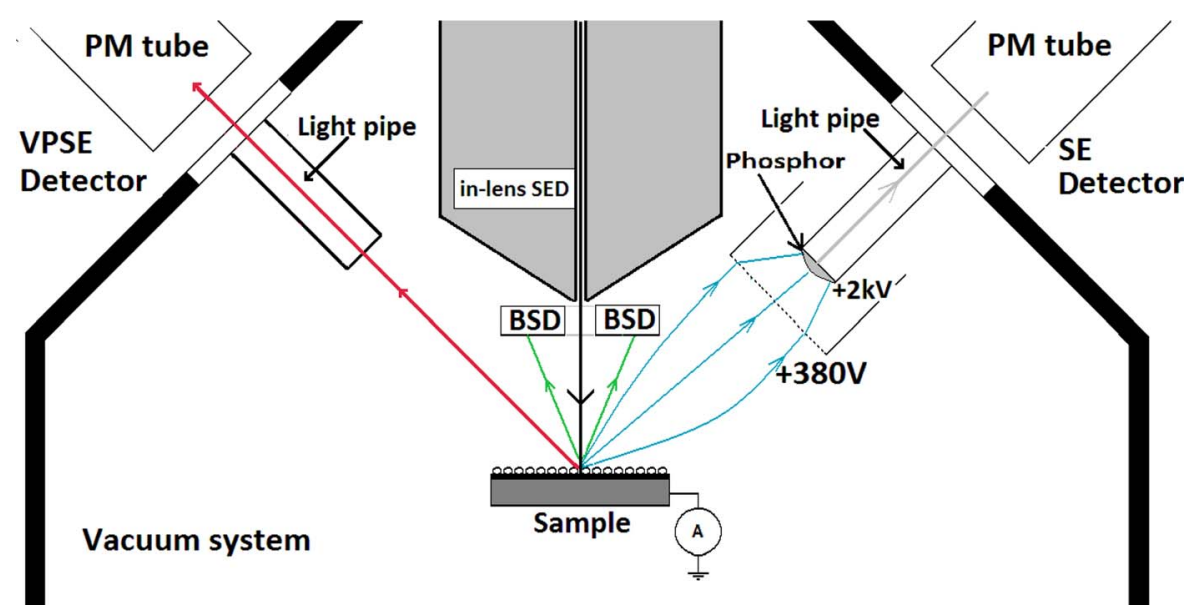

Figure 2. Arrangement of detectors in Zeiss Supra $35 \mathrm{VP}$. VPSE detector is the variable pressure detector that collects and amplifies CL-signals at high vacuum condition. BSD stands for backscatter detector. SE-detector is an Everhard-Thornley detector. The position of the in-lens SE detector is also indicated. 


\section{Electron gun $(\leqslant 15 \mathrm{kV})$}

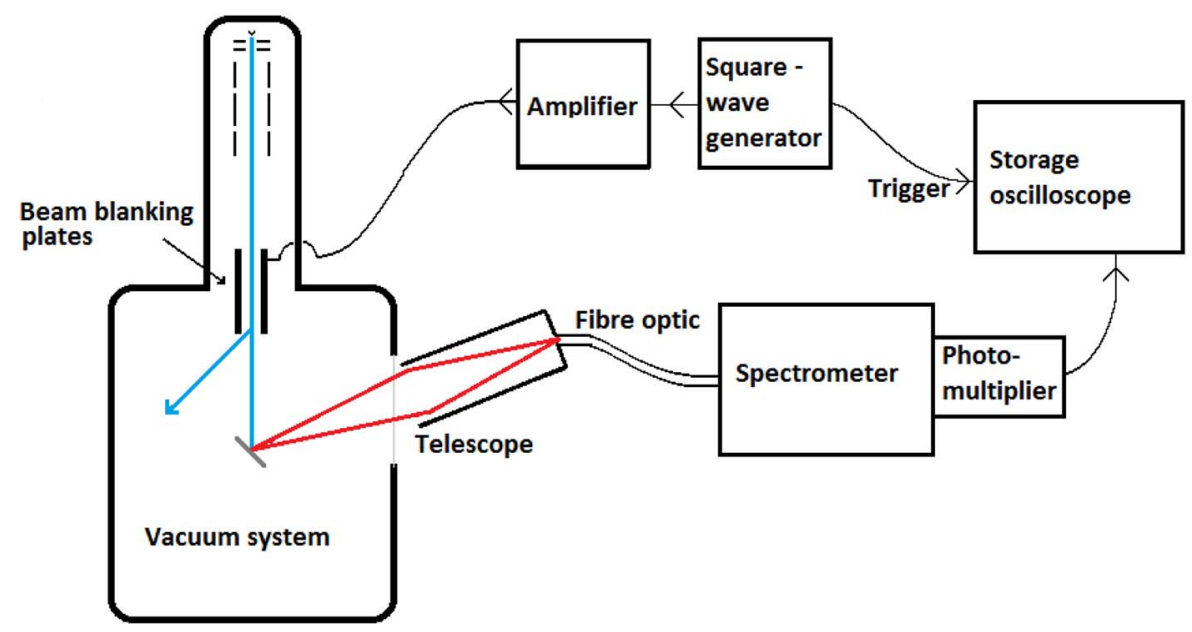

Figure 3. Measuring system for decay of spectral transitions. The spectrometer used in this system was a Bentham monochromator

The CL measurements for luminous efficiency and decay times were carried out in two different high vacuum chambers at a vacuum level of $\approx 3 \times 10^{-6}$ mbar using Kimball Physics Inc., USA, electron guns and associated power supplies over the ranges of electron beam voltages of $1-5 \mathrm{kV}$ and $3-15 \mathrm{kV}$ respectively. The electron guns had the ability to focus and defocus the beam over a range of current densities. For the studies of the luminous efficiency a uniform electron beam by defocusing and a current density of $1 \mu \mathrm{A} / \mathrm{cm}^{2}$ was used. Deflection plates enabled optimum positioning of the electron beam on the sample and a $\mathrm{ZnO}: \mathrm{Zn}$ reference. The latter being a non-charging thin film of $\mathrm{ZnO}: \mathrm{Zn}$ powder on ITO to adjust the current on the charging $\mathrm{Y}_{2} \mathrm{O}_{3}: \mathrm{Eu}^{3+}$ samples as explained in our previous work. ${ }^{1,2}$

For the determination of the luminous efficiency, spectral radiance and luminance were recorded with two Spectrobos 1200 spectroradiometers manufactured by JETI, Germany, between 380 and $780 \mathrm{~nm}$ in reflection and transmission mode. ${ }^{1,2}$ High resolution spectra $( \pm 0.1$ $\mathrm{nm}$ ) were also recorded with a Bentham, UK, monochromator detector system between 350 and $800 \mathrm{~nm}$. By blanking the E-beam of the Kimball electron gun we could measure the persistence behavior of various spectral transitions in $\mathrm{Y}_{2} \mathrm{O}_{3}: \mathrm{Eu}^{3+}$. The measuring system is schematically indicated in Figure 3.

The blanking speed was in the order of nano-seconds, orders of magnitude smaller than the decay times of the spectral transitions of $\mathrm{Y}_{2} \mathrm{O}_{3}: \mathrm{Eu}^{3+}$. The Bentham monochromator was used to tune the measuring wavelength to the maximum radiance of a particular spectral transition. Pulse frequency of the beam blanking system was $10 \mathrm{~Hz}$. All measurements were performed at room temperature (298 K).

\section{Results and Discussion}

FESEM characterisation.- Figure 4 represents a FESEM micrograph of monosized spherical $\mathrm{Y}_{2} \mathrm{O}_{3}: \mathrm{Eu}^{3+}$ particles forming a film electrophoretically deposited onto ITO coated glass slide. The particles are approximately $220 \mathrm{~nm}$ in diameter and form a highly dense layer with a low concentration of voids. As proof as to the monodispersity of the particles, when a solution is allowed to evaporate, a glasslike thick film is formed that displays a weak opalescence (which is determined by the diameter of the spherical particles and the close packing producing a modulation of the refractive index, as occurs in three-dimensional photonic bandgap crystals) as indeed this material formed has the optical characteristics of a bare opal.

Cathodoluminescence spectra.- Figure 5 shows CL spectra of films of monosized spherical $\mathrm{Y}_{2} \mathrm{O}_{3}: \mathrm{Eu}^{3+}$ nanoparticles excited by an electron beam of $15 \mathrm{keV}$ at a current density of $3 \mu \mathrm{A} / \mathrm{cm}^{2}$ and temperature of $298 \mathrm{~K}$. The spectra are normalized to 100 arbitrary units for the ${ }^{5} \mathrm{D}_{0} \rightarrow{ }^{7} \mathrm{~F}_{2}\left(\mathrm{C}_{2}\right)$ transition at $611 \mathrm{~nm}$ to indicate what trends can be observed for the weaker spectral transitions. For reasons of clarity the spectra with $10 \%, 4 \%, 3 \%, 0.8$ and 0.5 mole percent europium have not been inserted in Figure 5. The inset of Figure 5 shows the wavelength range between 570 and $605 \mathrm{~nm}$ in more detail. The strongest effect can be observed for the ${ }^{5} \mathrm{D}_{0} \rightarrow{ }^{7} \mathrm{~F}_{1 \mathrm{a}}\left(\mathrm{S}_{6}\right)$ transition at $582 \mathrm{~nm}$. The radiance is weak at $5 \% \mathrm{Eu}^{3+}$ and increases by about a factor of 4 for low $\mathrm{Eu}^{3+}$ concentrations. The same behavior can be observed for the transition at $592 \mathrm{~nm}$, although the effect is smaller than for the ${ }^{5} \mathrm{D}_{0} \rightarrow{ }^{7} \mathrm{~F}_{1 \mathrm{a}}\left(\mathrm{S}_{6}\right)$ transition. The peak at $592 \mathrm{~nm}$ is a combination of two transitions, viz. ${ }^{5} \mathrm{D}_{0} \rightarrow{ }^{7} \mathrm{~F}_{1 \mathrm{~b}}\left(\mathrm{~S}_{6}\right)$ and ${ }^{5} \mathrm{D}_{0} \rightarrow{ }^{7} \mathrm{~F}_{1 \mathrm{~b}}\left(\mathrm{C}_{2}\right)$ as was found by Hunt and Pappalardo: ${ }^{6}$ this explains that the increase of the normalized radiance of this peak at low $\mathrm{Eu}^{3+}$ concentration is less than for the $582 \mathrm{~nm}$ peak. The spectrum of $\mathrm{Y}_{2} \mathrm{O}_{3}: \mathrm{Eu}^{3+}$ with $0.01 \%$ $\mathrm{Eu}^{3+}$ exhibits a weak emission peak at $572 \mathrm{~nm}$, shown in the inset of Fig 5. This emission line cannot be assigned to any energy transition of $\mathrm{Y}_{2} \mathrm{O}_{3}: \mathrm{Eu}^{3+}$. It is therefore, confidently assigned to dysprosium contamination in the $\mathrm{Y}_{2} \mathrm{O}_{3}$ material used for the synthesis. Dysprosium has its main luminescence line at $572.5 \mathrm{~nm}$ which is due to the ${ }^{7} \mathrm{~F}_{9 / 2} \rightarrow{ }^{6} \mathrm{H}_{15 / 2}$ transitions; this main transition is not exhibited by the other lanthanides. The high purity yttrium oxide used in this work has a number of lanthanide contaminants at the parts per million concentration level. During our measurements a weak $\mathrm{Gd}^{3+}$ peak was observed at $314 \mathrm{~nm}$ (not shown in the spectra of Fig 5), which was also reported by Tanner et al. ${ }^{19}$ Since this $\mathrm{Gd}^{3+}$ transition was out of the range of interest of this work and any (very) low intensity peaks

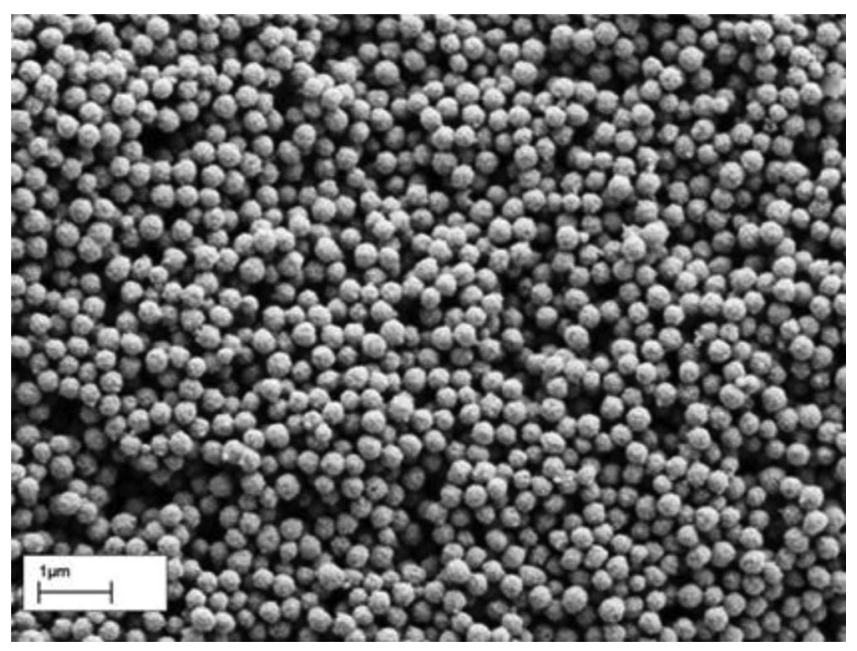

Figure 4. FESEM micrograph of a film of $\mathrm{Y}_{2} \mathrm{O}_{3}: \mathrm{Eu}^{3+}(0.1 \mathrm{Mol} \% \mathrm{Eu})$ on ITO-substrate at $3 \mathrm{keV}$ beam energy. 


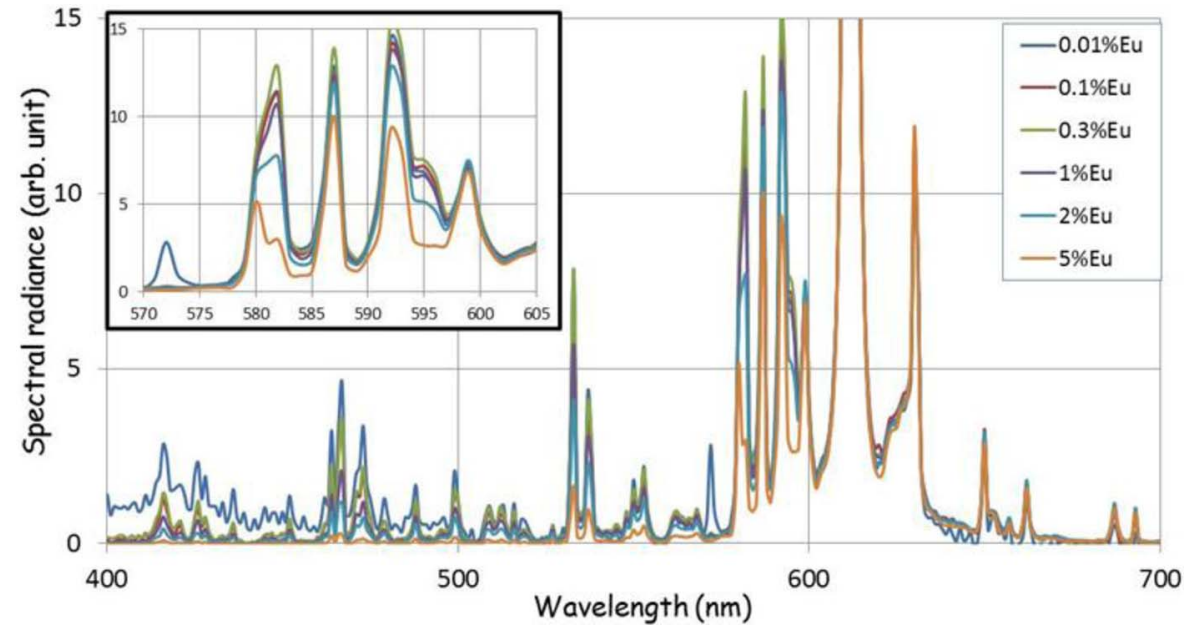

Figure 5. CL spectra of $\mathrm{Y}_{2} \mathrm{O}_{3}: \mathrm{Eu}^{3+}$ at various europium mole fractions. Beam energy $15 \mathrm{keV}$, current density $3 \mu \mathrm{A} / \mathrm{cm}^{2}$. Spectra are normalized to 100 arbitrary units for the ${ }^{5} \mathrm{D}_{0} \rightarrow{ }^{7} \mathrm{~F}_{2}\left(\mathrm{C}_{2}\right)$ transition at $611 \mathrm{~nm}$. of other lanthanide contaminants are hidden under the much stronger $\mathrm{Eu}^{3+}$ transitions, we assume that these contaminants do not affect the results of this study.

We shall now present a consideration on the energy transfer from $\mathrm{Eu}^{3+}$ in $\mathrm{S}_{6}$ to $\mathrm{Eu}^{3+}$ in $\mathrm{C}_{2}$ as described by others based on PL studies. ${ }^{4-8}$ As mentioned before, the ${ }^{5} \mathrm{D}_{0} \rightarrow{ }^{7} \mathrm{~F}_{1}\left(\mathrm{~S}_{6}\right)$ transition at $582 \mathrm{~nm}$ and the ${ }^{5} \mathrm{D}_{0} \rightarrow{ }^{7} \mathrm{~F}_{2}\left(\mathrm{C}_{2}\right)$ transition at $611 \mathrm{~nm}$ were selected for this study. The first step is determining the ratio between these two transitions: $\mathrm{R}_{611} / \mathrm{R}_{582}$. Figure 6 shows a deconvolution of the spectra around 582 and $611 \mathrm{~nm}$ : this deconvolution enables a determination of the radiances, $\mathrm{R}_{582}$ and $\mathrm{R}_{611}$.

It was assumed that the spectral transitions have Lorentzian shapes. The spectral radiance $\operatorname{SR}(\lambda)$, where $\lambda$ represents the wavelength, can be written as:

$$
S R(\lambda)=\sum_{i} \frac{A_{i}}{1+\frac{\left(\lambda-\lambda_{i}\right)^{2}}{b_{i}^{2}}}
$$
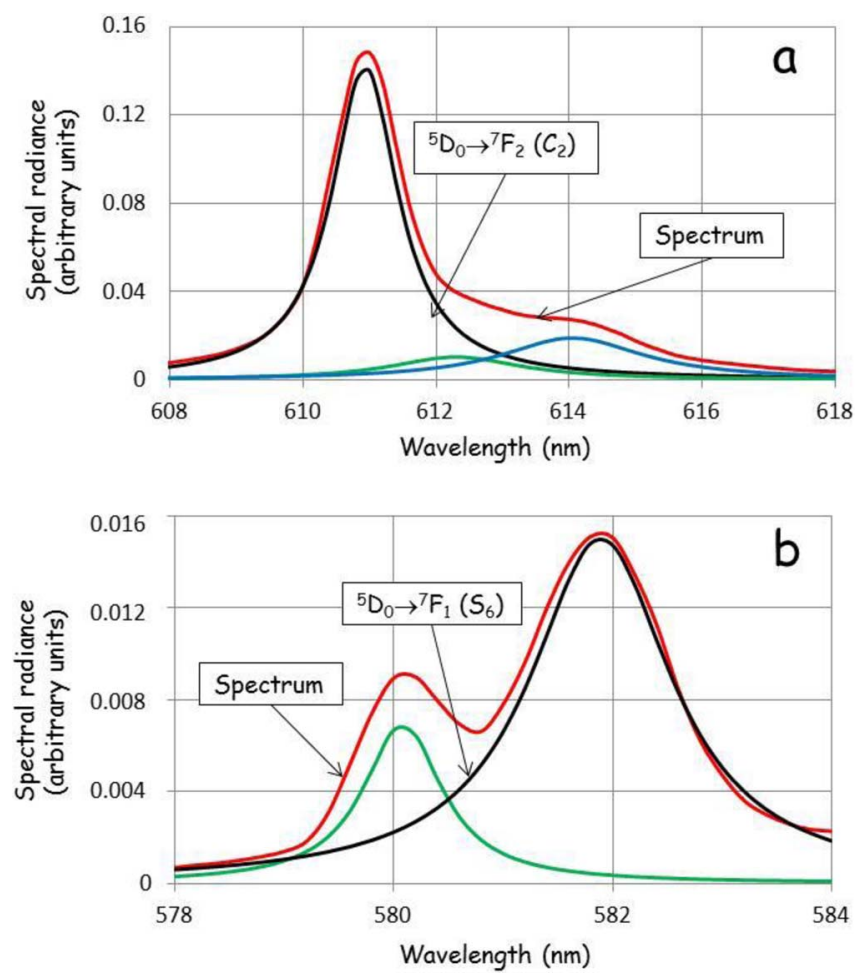

Figure 6. Deconvolution of parts of the CL spectrum of $\mathrm{Y}_{2} \mathrm{O}_{3}: \mathrm{Eu}^{3+}(0.8$ mole $\% \mathrm{Eu}$ ) at $15 \mathrm{kV}$ and $2 \mu \mathrm{A} / \mathrm{cm}^{2}$. (a) $611 \mathrm{~nm}$ region, (b) $582 \mathrm{~nm}$ region. where $A_{i}$ is the maximum spectral radiance of the $i^{\text {th }}$ peak, $\lambda_{i}$ is the wavelength for the maximum and $b_{i}$ is the half width at half maximum. The radiance of the $i^{\text {th }}$ transition is:

$$
R_{i}=\int_{-\infty}^{\infty} \frac{A_{i} d \lambda}{1+\frac{\left(\lambda-\lambda_{i}\right)^{2}}{b_{i}^{2}}}=A_{i} \pi b_{i}
$$

The relevant transitions are indicated in Figures $6 \mathrm{a}$ and $6 \mathrm{~b}$. Figure 6 indicates that the full width at half maximum (FWHM) of the $611 \mathrm{~nm}$ transition is smaller than that of $582 \mathrm{~nm}$ : viz. FWHM 611 $=1.22 \mathrm{~nm}$ and $\mathrm{FWHM}_{582}=1.58 \mathrm{~nm}$. For both transitions the FWHMs did not change as a function of $\mathrm{Eu}^{3+}$ concentration. It is assumed that the ratio $R_{611} / R_{583}$ is a relevant indicator of the energy flow from $S_{6}$ to $\mathrm{C}_{2}$ sites at short distances between $\mathrm{Eu}^{3+}$ ions. The spectra represented in Figures $6 \mathrm{a}$ and $6 \mathrm{~b}$ have also been deconvoluted with Gaussian peaks; for this deconvolution an extra peak was necessary for both spectral regions. The result of this convolution led to $\approx 33 \%$ lower values of the ratio $R_{611} / R_{583}$; however, the essential results and conclusions were the same.

Figure 7 shows two different plots of the radiance ratio $R_{611} / R_{582}$ : Figure $7 \mathrm{a}$ is a plot of this ratio versus the $\mathrm{Eu}^{3+}$ concentration and Figure $7 \mathrm{~b}$ is plot of the ratio versus the average distance $D_{\text {Eu }}$ between the $\mathrm{Eu}^{3+}$ ions in the $\mathrm{Y}_{2} \mathrm{O}_{3}$ lattice. This average distance in the cubic lattice is calculated according to:

$$
D_{E u}=\sqrt[3]{\frac{100 M}{2 \rho N c}}
$$

where $\mathrm{M}$ is the molecular weight of $\mathrm{Y}_{2} \mathrm{O}_{3}, \rho$ is the density of $\mathrm{Y}_{2} \mathrm{O}_{3}$, being $5.01 \mathrm{~g} / \mathrm{cm}^{3}$, and $\mathrm{N}$ is Avogadro's number. The factor 100 appears in Eq. 4, because $\mathrm{c}$ is expressed in \%.

If all $\mathrm{Y}^{3+}$ ions in the $\mathrm{Y}_{2} \mathrm{O}_{3}$ lattice would have been changed for $\mathrm{Eu}^{3+}$ ions, the average distance between the $\mathrm{Eu}^{3+}$ ions is $0.334 \mathrm{~nm}$ according to Eq. 4. In the $\mathrm{Y}_{2} \mathrm{O}_{3}$ lattice the shortest distance between the cation sites $\mathrm{C}_{2}$ and $\mathrm{S}_{6}$ is $0.352 \mathrm{~nm} ;{ }^{4}$ so, it can be concluded that Eq. 4 is a fair representation of the average distance between an $\mathrm{Eu}^{3+}$ ion at a $\mathrm{S}_{6}$ site and an $\mathrm{Eu}^{3+}$ ion at a $\mathrm{C}_{2}$ site as a function of the $\mathrm{Eu}^{3+}$ concentration.

Figures $7 \mathrm{a}$ and $7 \mathrm{~b}$ show that the radiance ratio $\mathrm{R}_{611} / \mathrm{R}_{582}$ is essentially constant in the range between 0.01 and $0.5 \% \mathrm{Eu}^{3+}$.

The diamonds in Figures $7 \mathrm{a}$ and $7 \mathrm{~b}$ represent the experimental results obtained with the algorithm described in Eqs. 2 and 3; the dashed curves are best fits to these results.

These curves can be represented by the following phenomenological equations:

$$
\frac{R_{611}}{R_{582}}=G+H_{1} c^{\delta}
$$



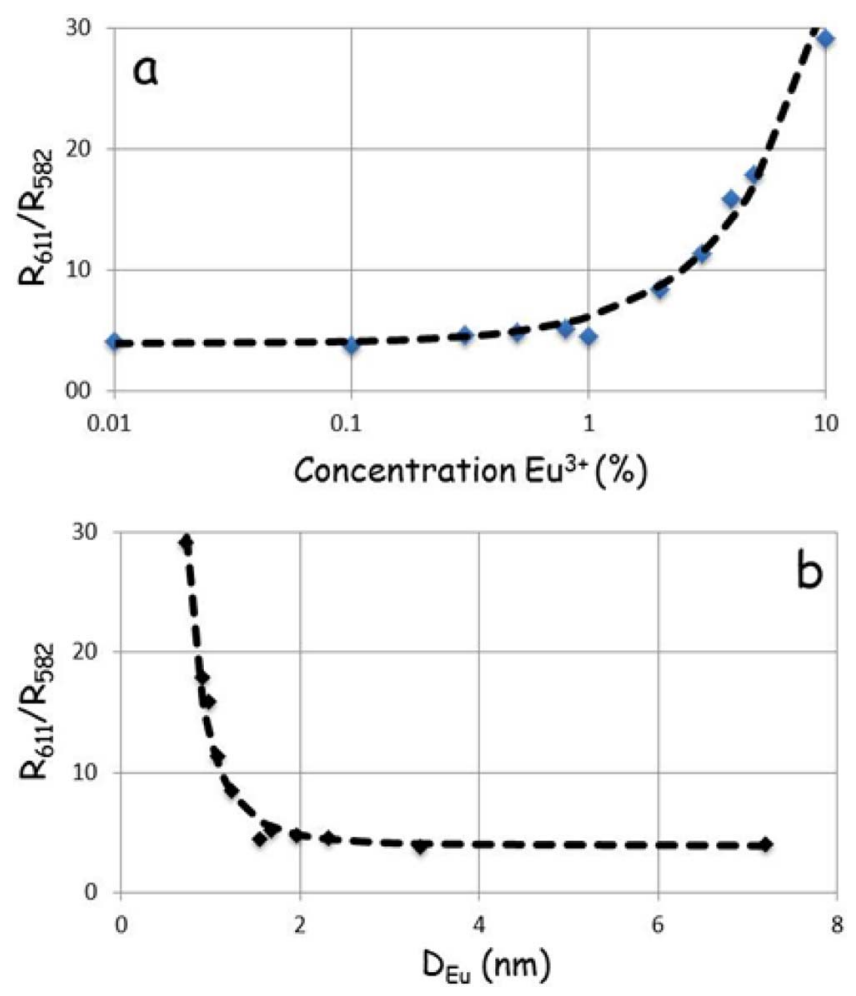

Figure 7. (a) Radiance ratio $\mathrm{R}_{611} / \mathrm{R}_{582}$ versus mole fraction of europium in $\mathrm{Y}_{2} \mathrm{O}_{3}: \mathrm{Eu}^{3+}$. (b) Radiance ratio $\mathrm{R}_{611} / \mathrm{R}_{582}$ versus $\mathrm{Eu}^{3+}: \mathrm{Eu}^{3+}$ distance in the $\mathrm{Y}_{2} \mathrm{O}_{3}$ lattice.

and

$$
\frac{R_{611}}{R_{583}}=G+H_{2} D_{E u}^{-3 \delta}
$$

The parameters $\mathrm{G}$ and $\delta$ in Eqs. (5a) and (5b) respectively have the same values; so, the exponent of $\mathrm{D}_{\mathrm{Eu}}$ in Eq. (5b) is 3 times larger than then the exponent of the concentration $\mathrm{c}$ in Eq. (5a), because of Eq. 4. The values of $\mathrm{G}, \mathrm{H}_{1}, \delta$ and $\mathrm{H}_{2}$ are 5.8, 2.9, 1.1 and 14 respectively. Since the steepness of the fitted curve in Figure $7 \mathrm{~b}$ is larger than that in Figure 7a it allows a better estimate of the knee point of the curve, being $1.7 \mathrm{~nm}$. In Figure $7 \mathrm{a}$ this would be equivalent to a concentration of 0.8 mole $\% \mathrm{Eu}^{3+}$. In other words, the critical distance, crit $D_{E u}$, for interaction between the $S_{6}$ and $C_{2}$ sites is $1.7 \mathrm{~nm}$.

In the literature one usually defines a parameter $\mathrm{R}_{0}$, being the critical transfer distance, for which the transfer rate of energy from $\mathrm{S}_{6}$ to $\mathrm{C}_{2}$ is equal to the radiative decay rate. ${ }^{7}$ Values published for $\mathrm{R}_{0}$ of $\mathrm{Eu}^{3+}$ cations in the cubic $\mathrm{Y}_{2} \mathrm{O}_{3}$ are $0.87 \mathrm{~nm},{ }^{4} 0.82 \mathrm{~nm}^{7}$ and $0.86 \mathrm{~nm} .{ }^{25}$ By constructing two spheres both with a radius of $\mathrm{R}_{0}$, the first centered at an $\mathrm{S}_{6}$ site and the second centered at a $\mathrm{C}_{2}$ site, energy transfer from $S_{6}$ to $C_{2}$ is possible when the spheres overlap. With this picture in mind it is easy to conclude that the critical distance $D_{E u}$ as concluded from Figure $7 b$, is equal to $2 R_{0}$; so, we get $R_{0}=0.85 \mathrm{~nm}$, which matches well with the published values of $R_{0}$.

From this straightforward spectral analysis it can be concluded that an evaluation of the critical energy transfer distance is possible without extensive analyses on the decay of the emission at various temperatures (which is the most used method of evaluation). Klaassen et al. ${ }^{8}$ also presented the relative intensity from excited ${ }^{5} \mathrm{D}_{\mathrm{J}}$ levels to the ${ }^{7} \mathrm{~F}_{\mathrm{J}}$-multiplets under stationary electron bombardment at low current density as a function of the $\mathrm{Eu}^{3+}$ concentration. Although their highest $\mathrm{Eu}^{3+}$ concentration was only $1 \%$, the knee in their simulated curve was at $\approx 0.3 \% \mathrm{Eu}^{3+}$, slightly different from our result. The analysis of Klaassen et al. was based on the evaluation of radiative decay times and non-radiative decay rates.
Luminous efficiency. - Thin films of $\mathrm{Y}_{2} \mathrm{O}_{3}: \mathrm{Eu}^{3+}$ mono-sized particles deposited on ITO coated glass slides were used for measuring the luminance and spectral radiance. The weight of the $\mathrm{Y}_{2} \mathrm{O}_{3}$ :Eu films was $2 \mathrm{mg} / \mathrm{cm}^{2}$. From Figure 4 it can be concluded that the monosized spherical $\mathrm{Y}_{2} \mathrm{O}_{3}: \mathrm{Eu}^{3+}$ nanoparticles had a random close packing, although there were areas with a higher packing density. Random close packing gives a packing density of 0.64 . The film thickness $F$ is calculated using a packing density of 0.65 , slightly larger than 0.64 , with:

$$
F=\frac{W}{\rho B}
$$

where $\mathrm{W}$ is the coating weight, $\rho$ is the density of crystalline phosphor material, $5.0 \mathrm{~g} / \mathrm{cm}^{3}$ for $\mathrm{Y}_{2} \mathrm{O}_{3}: \mathrm{Eu}^{3+}$, and $\mathrm{B}$ is the packing density in the layer. ${ }^{1}$ With these values for $\mathrm{W}, \rho$ and $\mathrm{B}$ the film thickness $\mathrm{F}$ is $6.2 \mu \mathrm{m}$. The penetration depth of $15 \mathrm{keV}$ electrons in crystalline $\mathrm{Y}_{2} \mathrm{O}_{3}$ is $1.9 \mu \mathrm{m}^{2}$; so, it can safely be assumed that the electron energy is absorbed for more than $99 \%$ in the phosphor layer.

Figure 8 a represents the luminous efficiency calculated from the luminance measured in the transmission and reflection modes; for reasons of clarity not all data have been inserted in the graph. The evaluation method for the luminous efficiency has been indicated in detail in our previous work. ${ }^{1,2}$ It can be seen that the luminous efficiency is essentially constant between 7 and $15 \mathrm{kV}$. In Figure $8 \mathrm{~b}$ the luminous efficiency is plotted as a function of the mole fraction of Eu. The results of Yang et al., ${ }^{11}$ which are also plotted in Figure 8b, refer to micrometer sized $\mathrm{Y}_{2} \mathrm{O}_{3}: \mathrm{Eu}^{3+}$ particles and measurements at $4 \mathrm{kV}$.

From our data represented in Figure $8 \mathrm{~b}$ it can be concluded that between 1 and $2 \%$ mole $\% \mathrm{Eu}^{3+}$ in $\mathrm{Y}_{2} \mathrm{O}_{3}$ the maximum luminous efficiency of $\approx 16 \mathrm{~lm} / \mathrm{w}$ at $15 \mathrm{keV}$ electron energy is obtained. This corresponds to an energy efficiency of $5.2 \%$. This result is higher than we found before. ${ }^{2}$ The reason for the rather low efficiency in ${ }^{2}$ was the non-uniformity of the settled layers: especially in the center area of the ITO substrate the films were thinner and it is assumed that not all electron energy was transferred to the phosphor at high beam energy. In the present study the quality of the electrophoretic layers is better, as
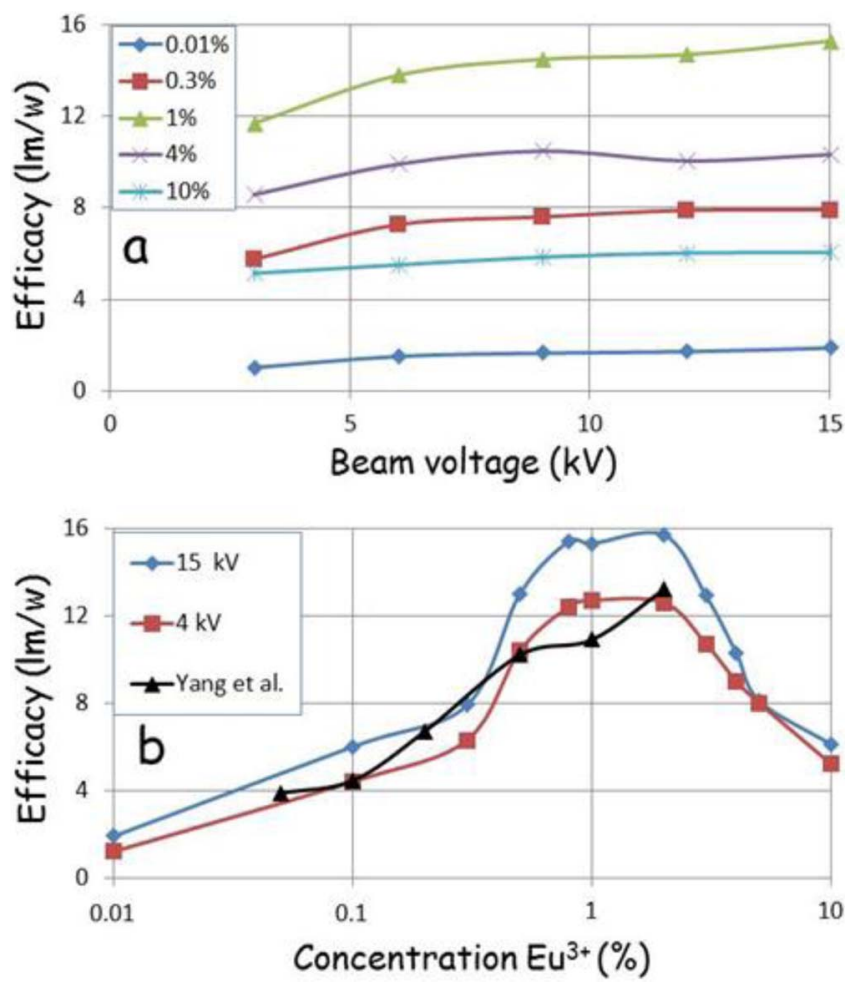

Figure 8. (a) Luminous efficacy as a function of the voltage of the electron beam. (b) Luminous efficacy as a function of $\mathrm{Eu}^{3+}$ mole fraction at 4 and $15 \mathrm{kV}$. The results of Yang et al. ${ }^{11}$ at $4 \mathrm{kV}$ are also plotted. 


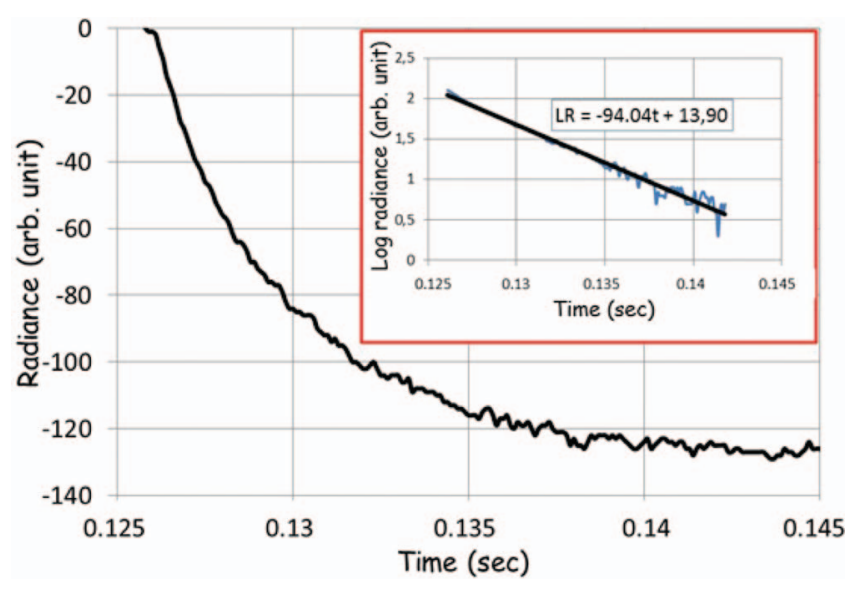

Figure 9. Decay curve of $\mathrm{Y}_{2} \mathrm{O}_{3}: \mathrm{Eu}^{3+} 2 \%:{ }^{5} \mathrm{D}_{0} \rightarrow{ }^{7} \mathrm{~F}_{1 \mathrm{a}}\left(\mathrm{S}_{6}\right)$ transition at 582 $\mathrm{nm}$. The inset shows the logarithm of the radiance (LR) as a function of time.

shown in Figure 4. Jiang et al. ${ }^{14}$ found that nanocrystalline $\mathrm{Y}_{2} \mathrm{O}_{3}: \mathrm{Eu}^{3+}$ excited by an electron beam had the highest luminous efficiency at an $\mathrm{Eu}^{3+}$ concentration of $2.5 \%$. For nanocrystalline $\mathrm{Y}_{2} \mathrm{O}_{3}: \mathrm{Eu}^{3+}$ with $2 \% \mathrm{Eu}^{3+}$ they evaluated a luminous efficiency of $11.5 \mathrm{~lm} / \mathrm{w}$ at $4 \mathrm{keV}$ beam energy from the measurement of the luminance in the reflection mode only. Our results provide a value of $12.6 \mathrm{~lm} / \mathrm{w}$ at $4 \mathrm{keV}$, which is slightly larger than the result of Jiang et al.

Finally it was noted that the highest efficiency of $\mathrm{Y}_{2} \mathrm{O}_{3}: \mathrm{Eu}^{3+}$ nanoparticles with $2 \% \mathrm{Eu}^{3+}$ is about $30 \%$ lower than that of micrometer sized $\mathrm{Y}_{2} \mathrm{O}_{3}: \mathrm{Eu}^{3+}$ particles. ${ }^{10}$ It is well known that the CL efficiency of nanoparticles is smaller than that of the corresponding micrometer sized particles. ${ }^{11,13}$ This effect is usually attributed to the surface, which is much larger for nanoparticles than for micrometer particles.

Decay. - Thin films of monosized spherical $\mathrm{Y}_{2} \mathrm{O}_{3}: \mathrm{Eu}^{3+}$ nanoparticles were excited with a defocused electron beam of $15 \mathrm{kV}$ and current density of $3 \mu \mathrm{A} / \mathrm{cm}^{2}$. Saturation did not occur at this current density under stationary conditions, as will be shown in the next section on the observations in the FESEM. A typical decay curve is presented in Figure 9.

With a blanking frequency of $10 \mathrm{~Hz}$ the time for the beam on was $50 \mathrm{~ms}$, which is much longer than the reported decay times of $\mathrm{Y}_{2} \mathrm{O}_{3}: \mathrm{Eu}^{3+} .8$ So, it can be assumed that the energy flow in the $\mathrm{Y}_{2} \mathrm{O}_{3}: \mathrm{Eu}^{3+}$ nanoparticles was in a steady state at switching off the electron beam.

The decay curves recorded during this study can be represented by a single exponential function. The time constant $\tau$ of the decay has been evaluated from a log plot of the decay curve shown in the inset of Figure 9. In some cases a correction for the background has been applied. The inset in Figure 9 shows the algebraic representation of the regression line. From the coefficient before the parameter $\mathrm{t}$ the non-corrected time constant can be calculated according to $434.4 / 94.04=4.6 \mathrm{~ms}$. From this value an equipment correction of $0.3 \mathrm{~ms}$ must be subtracted to get the time constant of the ${ }^{5} \mathrm{D}_{0} \rightarrow{ }^{7} \mathrm{~F}_{1 \mathrm{a}}$ $\left(\mathrm{S}_{6}\right)$ transition.

Table I shows the time constants in ms for the various spectral transitions and samples measured during this investigation. The accuracy for the ${ }^{5} \mathrm{D}_{0} \rightarrow{ }^{7} \mathrm{~F}_{2}\left(\mathrm{C}_{2}\right)$ transition at $611 \mathrm{~nm}$ is about $\pm 3 \%$. For the other spectral transitions the accuracy is between \pm 5 and $\pm 10 \%$. The $S_{6}$ transitions are magnetic dipole transitions and it is therefore expected that the time constant of the decay is longer than for corresponding (allowed) $\mathrm{C}_{2}$ transitions. This behavior is reflected in the time constants listed in Table I. The time constant of the ${ }^{5} \mathrm{D}_{0} \rightarrow{ }^{7} \mathrm{~F}_{2}$ $\left(C_{2}\right)$ transition is shorter than that of the ${ }^{5} \mathrm{D}_{0} \rightarrow{ }^{7} \mathrm{~F}_{1 \mathrm{a}}\left(\mathrm{S}_{6}\right)$ transition, while the mixed peak at $592 \mathrm{~nm}$ has an intermediate value, because it is made up of a combination of a $\mathrm{C}_{2}$ and $\mathrm{S}_{6}$ transition, as indicated before. The ${ }^{5} \mathrm{D}_{1} \rightarrow{ }^{7} \mathrm{~F}_{1}\left(\mathrm{C}_{2}\right)$ transition at $533 \mathrm{~nm}$ has a much shorter

\begin{tabular}{|c|c|c|c|}
\hline $\mathrm{Eu}^{3+}(\%)$ & $\begin{array}{c}{ }^{5} \mathrm{D}_{0} \rightarrow{ }^{7} \mathrm{~F}_{2} \\
\left(\mathrm{C}_{2}\right)(611 \mathrm{~nm})\end{array}$ & $\begin{array}{c}{ }^{5} \mathrm{D}_{0} \rightarrow{ }^{7} \mathrm{~F}_{1} \\
\left(\mathrm{~S}_{6}\right)(582 \mathrm{~nm})\end{array}$ & $\begin{array}{c}{ }^{5} \mathrm{D}_{0} \rightarrow{ }^{7} \mathrm{~F}_{1} \\
\left(\mathrm{C}_{2} / \mathrm{S}_{6}\right)(592 \mathrm{~nm})\end{array}$ \\
\hline 10 & 0.70 & 1.0 & 0.77 \\
\hline 5 & 0.92 & 1.8 & 1.2 \\
\hline 4 & 0.96 & 2.6 & 1.5 \\
\hline 3 & 1.03 & 3.4 & 1.6 \\
\hline 2 & 1.06 & 4.3 & 1.7 \\
\hline 1 & 1.05 & 4.8 & 1.7 \\
\hline 0.8 & 1.02 & 5.8 & 1.7 \\
\hline 0.5 & 1.03 & 6.5 & 2.5 \\
\hline 0.3 & 1.02 & 5.6 & 1.7 \\
\hline 0.1 & 0.95 & 4.5 & \\
\hline 0.01 & 0.99 & & \\
\hline
\end{tabular}

time constant, $<50 \mu \mathrm{s}$. Because of the limitations of our equipment, it was not possible to measure an accurate value for this time constant.

The time constants vary as a function of $\mathrm{Eu}^{3+}$ concentration: for the ${ }^{5} \mathrm{D}_{0} \rightarrow{ }^{7} \mathrm{~F}_{2}\left(\mathrm{C}_{2}\right)$ transition at $611 \mathrm{~nm}$; they stabilize at $1.02 \mathrm{~ms}$ for concentrations $<1 \% \mathrm{Eu}^{3+}$. Klaassen et al. ${ }^{8}$ also observed in their PL-experiments that time constants of the transitions in $\mathrm{Y}_{2} \mathrm{O}_{3}: \mathrm{Eu}^{3+}$ with high $\mathrm{Eu}^{3+}$-concentration are smaller than those with lower $\mathrm{Eu}^{3+}$ concentrations; they attributed this effect to concentration quenching. According to their analysis, the reciprocal time constant $1 / \tau$ can be written as:

$$
1 / \tau=1 / \tau_{r}+A c^{\gamma}
$$

where $\tau_{\mathrm{r}}$ is the radiative time constant and the second term represents the radiationless decay rate, $\mathrm{c}$ is the concentration of $\mathrm{Eu}^{3+}$ in $\%$ and A and $\gamma$ are parameters that are fitted to the measured time constants .

The data listed in Table I are visualized in Figures 10a and 10b: as a function of $\mathrm{Eu}^{3+}$ concentration and as function of the average $\mathrm{Eu}^{3+}$ $: \mathrm{Eu}^{3+}$ distance in the $\mathrm{Y}_{2} \mathrm{O}_{3}: \mathrm{Eu}^{3+}$ lattice respectively.

From Figures $10 \mathrm{a}$ and $10 \mathrm{~b}$ it can be concluded that the radiative decay time for ${ }^{5} \mathrm{D}_{0} \rightarrow{ }^{7} \mathrm{~F}_{2}\left(\mathrm{C}_{2}\right)$ is $1.04 \mathrm{~ms}$ and for ${ }^{5} \mathrm{D}_{0} \rightarrow{ }^{7} \mathrm{~F}_{1}\left(\mathrm{~S}_{6}\right)$ it is $5.4 \mathrm{~ms}$, which is in fair agreement with the results of Klaassen et al. ${ }^{8}$ By inserting Eq. 4 in (7) we get:

$$
1 / \tau=1 / \tau_{r}+A^{*} D_{E u}{ }^{-3 \gamma}
$$

Figure $10 \mathrm{~b}$ shows $1 / \tau$ versus $\mathrm{D}_{\mathrm{Eu}}$, which is the average $\mathrm{Eu}^{3+}: \mathrm{Eu}^{3+}$ distance in $\mathrm{Y}_{2} \mathrm{O}_{3}: \mathrm{Eu}^{3+}$, (depending on the tri-positive europium concentration in the yttrium oxide host lattice) for the ${ }^{5} \mathrm{D}_{0} \rightarrow{ }^{7} \mathrm{~F}_{2}\left(\mathrm{C}_{2}\right)$ transition at $611 \mathrm{~nm}$ and the ${ }^{5} \mathrm{D}_{0} \rightarrow{ }^{7} \mathrm{~F}_{1}\left(\mathrm{~S}_{6}\right)$ transition at $582 \mathrm{~nm}$. The parameters used for the calculation of the dashed curves in Figure 10b are listed in Table II. It can be seen in Table II that $3 \gamma$ is 6 for ${ }^{5} \mathrm{D}_{0} \rightarrow{ }^{7} \mathrm{~F}_{2}$ $\left(C_{2}\right)$ and 5.8 for ${ }^{5} D_{0} \rightarrow{ }^{7} F_{1}\left(S_{6}\right)$ : the exponent of $D_{E u}$ in Eq. (7a) is $\approx-6$ for both transitions. So, it can be concluded that dipole-dipole interaction for both transitions causes the decrease of the decay time at higher $\mathrm{Eu}^{3+}$ concentrations. The difference between the two curves is the value of the factor $A *$, which is much larger for the ${ }^{5} \mathrm{D}_{0} \rightarrow{ }^{7} \mathrm{~F}_{1}$ $\left(\mathrm{S}_{6}\right)$ transition.

Table III shows a comparison of the time constants of decay curves of $\mathrm{Y}_{2} \mathrm{O}_{3}: \mathrm{Eu}^{3+}$ of various transitions measured by other workers. The agreement is satisfactory, although it is difficult to draw conclusions on the concentration effect of $\mathrm{Eu}^{3+}$ in $\mathrm{Y}_{2} \mathrm{O}_{3}: \mathrm{Eu}^{3+}$, because its concentration is not always stated in the references cited in Table II.

FESEM observations. - Figure 11 shows FESEM images of monosized spherical $\mathrm{Y}_{2} \mathrm{O}_{3}: \mathrm{Eu}^{3+}$ nanoparticles on a polished aluminum pin stub (the polishing features can clearly be observed). Aluminum pin stubs were chosen to reflect some of the light generated in the particles in order to maximize the photon collection in the light pipe of the variable pressure secondary electron (VPSE) detector as indicated in Figure 2. Figures 11a and 11b are images of the same area, Figure 11a is the SE-micrograph and $11 \mathrm{~b}$ is the 

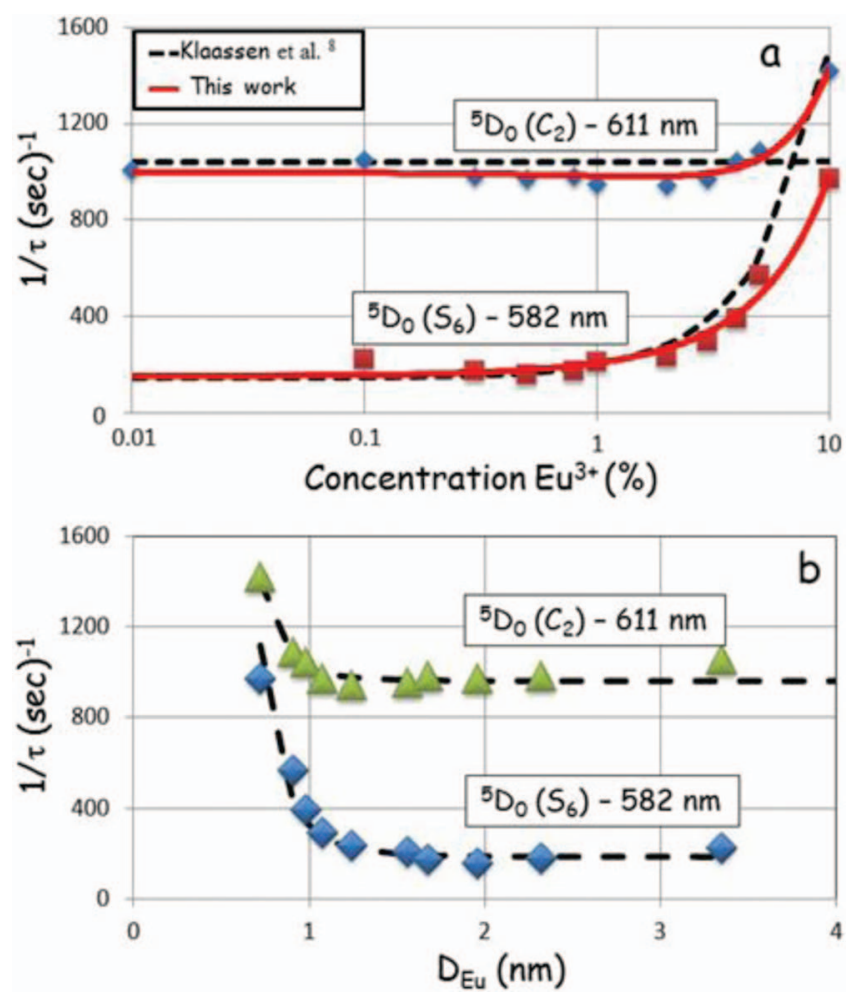

Figure 10. Reciprocal time constants for the ${ }^{5} \mathrm{D}_{0} \rightarrow{ }^{7} \mathrm{~F}_{2}\left(\mathrm{C}_{2}\right)$ transition at 611 $\mathrm{nm}$ and ${ }^{5} \mathrm{D}_{0} \rightarrow{ }^{7} \mathrm{~F}_{1}\left(\mathrm{~S}_{6}\right)$ transition at $582 \mathrm{~nm}$ plotted versus $\mathrm{Eu}^{3+}$-concentration in (a), and versus $\mathrm{Eu}^{3+}: \mathrm{Eu}^{3+}$ distance in (b). Triangles and diamonds are experimental results; dashed curves in $\mathrm{b}$ are calculated according to Eq. $7 \mathrm{a}$. The results of Klaassen et al. ${ }^{8}$ are also represented in (a).

Table II. Parameters for decay curves represented in Figure 10b.

\begin{tabular}{ccc} 
Parameter & ${ }^{5} \mathrm{D}_{0} \rightarrow{ }^{7} \mathrm{~F}_{1 \mathrm{a}}\left(\mathrm{C}_{2}\right)(611 \mathrm{~nm})$ & ${ }^{5} \mathrm{D}_{0} \rightarrow{ }^{7} \mathrm{~F}_{1}\left(\mathrm{~S}_{6}\right)(582 \mathrm{~nm})$ \\
\hline $1 / \tau_{\mathrm{r}}(\mathrm{ms})$ & 1.04 & 5.4 \\
$\mathrm{~A} *$ & 62 & 140 \\
$\gamma$ & 2.0 & 1.9
\end{tabular}

CL-micrograph. The SE-micrograph is a clear picture and shows details of the particles, whereas in the CL-micrograph the nanoparticles are smeared out in the horizontal direction and show a comet-like tail. The reason for this blurring is the decay of $\mathrm{CL}$ in $\mathrm{Y}_{2} \mathrm{O}_{3}: \mathrm{Eu}^{3+}$. So, the smearing of CL-images offers the opportunity to measure decay times of CL-phosphors. ${ }^{3}$ Figure $11 \mathrm{~b}$ shows a halo effect, which is particularly visible for clusters of $\mathrm{Y}_{2} \mathrm{O}_{3}: \mathrm{Eu}^{3+}$ nanoparticles. The halo is caused by BSEs emitting from the aluminium-substrate positions around the $\mathrm{Y}_{2} \mathrm{O}_{3}: \mathrm{Eu}^{3+}$ nanoparticles or clusters. These BSEs may also hit the phosphor nanoparticle and since the energy of the BSEs is large enough, $C L$ is generated.

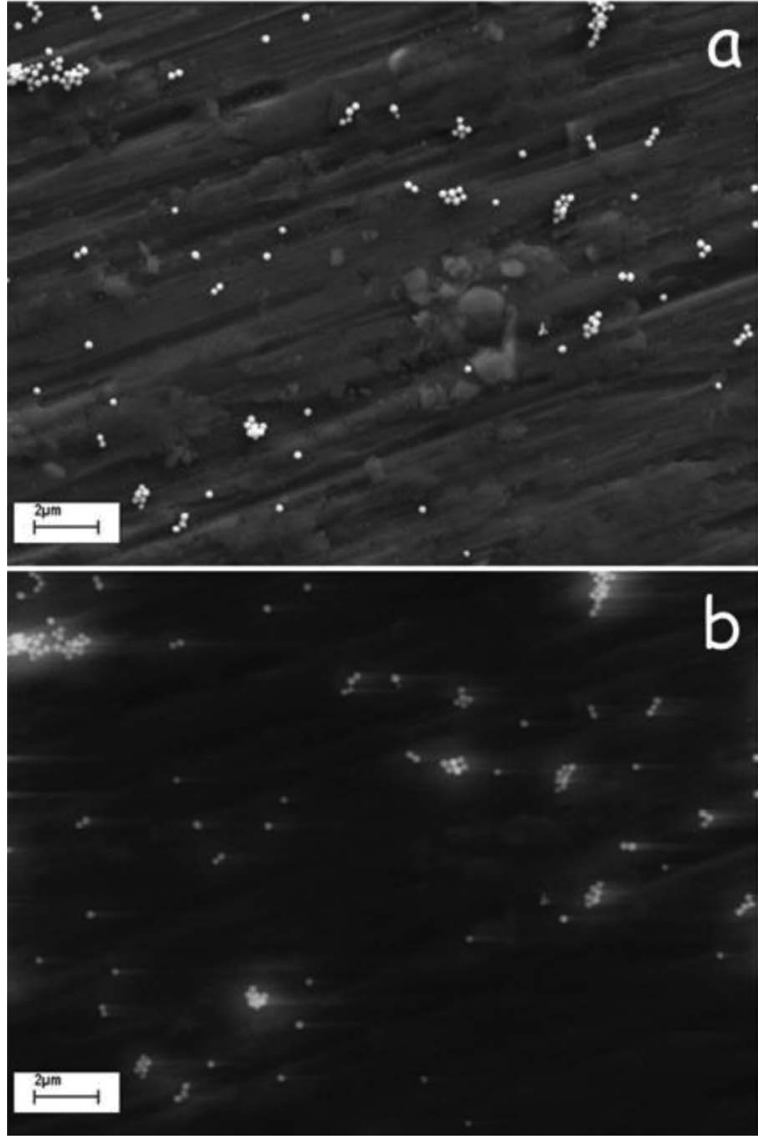

Figure 11 (a) SE-micrograph of $\mathrm{Y}_{2} \mathrm{O}_{3}: \mathrm{Eu}^{3+}\left(2 \% \mathrm{Eu}^{3+}\right)$ nanoparticles on an Al-substrate. Beam energy: 10keV. b: CL-micrograph of the same area and same beam energy. Recorded at 20.2 seconds/frame.

Figure 12 summarizes the most important feature of the CLmicrographs, viz. that the smearing out in the horizontal direction decreases and virtually disappears for $\mathrm{Y}_{2} \mathrm{O}_{3}: \mathrm{Eu}^{3+}$ nanoparticles with low $\mathrm{Eu}^{3+}$ concentration. The decay curves of some individual nanoparticles have been analyzed with ImageJ software and the results are summarized in Table IV. Table IV shows that the time constant decreases at low $\mathrm{Eu}^{3+}$ concentration. At 0.1 and $0.01 \% \mathrm{Eu}^{3+}$ no horizontal tail can be observed for a dwell time of $260 \mu$ s per nanoparticles. However, by decreasing the dwell time to $2.5 \mu \mathrm{s}$, the tail becomes visible again as shown in Figure 12.

The results presented in Figure 12 and Table IV will be interpreted in terms of saturation of the CL. The parameters that determine the degree of saturation under electron bombardment, i.e. loss of efficiency, are current density $j$, activator concentration $c$, time constant $\tau$ of the spectral transition and duration of the pulse $\Delta \mathrm{t}$ in non-stationary conditions. ${ }^{8,9}$ Let us first consider the current density in the electron microscope. In focused condition the spot size of the electron beam

Table III. Comparison of time constants (in ms) of luminescence decay of $\mathrm{Y}_{2} \mathrm{O}_{3}: \mathrm{Eu}^{3+}$.

\begin{tabular}{|c|c|c|c|c|c|}
\hline${ }^{5} \mathrm{D}_{0} \rightarrow{ }^{7} \mathrm{~F}_{2}\left(\mathrm{C}_{2}\right) 611 \mathrm{~nm}$ & ${ }^{5} \mathrm{D}_{0} \rightarrow{ }^{7} \mathrm{~F}_{1 \mathrm{a}}\left(\mathrm{S}_{6}\right) 582 \mathrm{~nm}$ & ${ }^{5} \mathrm{D}_{1} \rightarrow{ }^{7} \mathrm{~F}_{1}\left(\mathrm{C}_{2}\right) 533 \mathrm{~nm}$ & Not specified & Remark & Ref. \\
\hline 1.76 & & & & PL & 15 \\
\hline 1.2 & & & & PL: YAG-Nd 532nm & 16 \\
\hline 0.96 & 6.9 & $0.091)$ & & PL: $0.01 \% \mathrm{Eu}$ & 8 \\
\hline & & & 1.1 & CL: $4 \mathrm{keV}$ & 26 \\
\hline 1.1 & 7.9 & & & PL & 7 \\
\hline & & & 1.2 & $\mathrm{CL}: 1 \mathrm{kV}$ and $1 \mu \mathrm{A} / \mathrm{cm}^{2}$ & 10 \\
\hline 0.97 & 5.5 & $\begin{array}{l}0.08 \\
<0.05\end{array}$ & & $\begin{array}{l}\text { CL: } 4 \mathrm{kV} 4.6 \% \mathrm{Eu} \\
\text { CL: } 15 \mathrm{kV} 0.1 \% \mathrm{Eu}\end{array}$ & $\begin{array}{c}27 \\
\text { This work }\end{array}$ \\
\hline
\end{tabular}




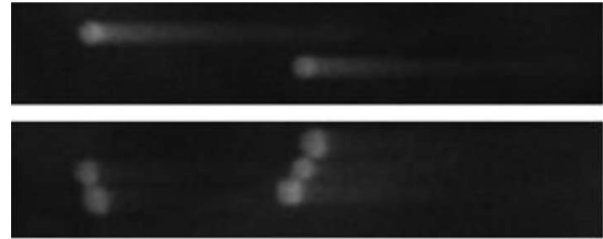

$5 \%$

$2 \%$

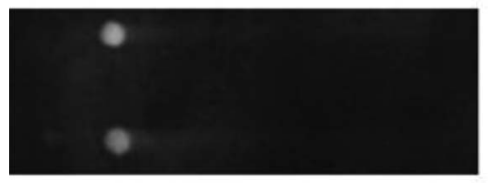

$1 \%$
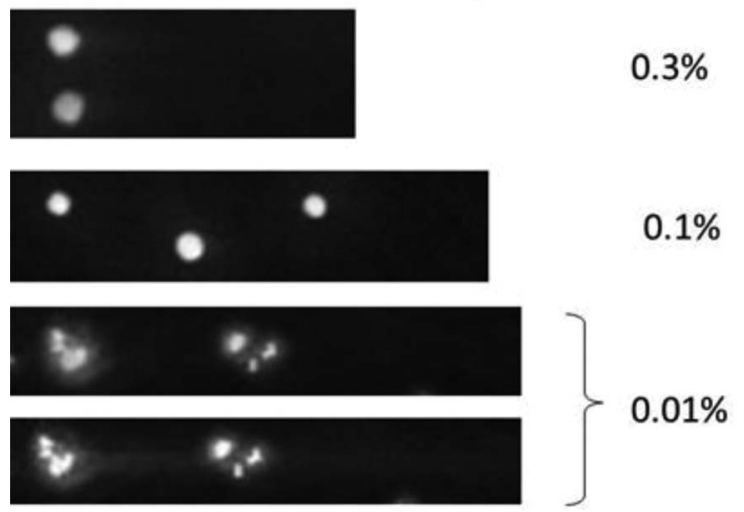

Figure 12. CL-micrographs of $\mathrm{Y}_{2} \mathrm{O}_{3}: \mathrm{Eu}^{3+}$ nanospheres with various $\mathrm{Eu}^{3+}$ concentrations at $10 \mathrm{keV}$. Dwell time of the E-beam on one sphere is $260 \mu \mathrm{s}$. For the $0.01 \% \mathrm{Eu}^{3+}$ sample the magnification is smaller. For the image of scan speed 9 (ss9) the dwell time is $40 \mu \mathrm{s}$ and for ss 5 it is $2.5 \mu \mathrm{s}$.

is $2 \mathrm{~nm}$ and the current is about $1 \mathrm{nA}$ in the FESEM. This yields a current density at the position where the beam hits the phosphor of $3 \times 10^{4} \mathrm{~A} / \mathrm{cm}^{2}$. This current density is so high that $\mathrm{Y}_{2} \mathrm{O}_{3}: \mathrm{Eu}^{3+}$ will hardly emit any light, contrary to what is observed in Figures 11 and 12. Thus, the effective current density must be lower and its value can be estimated by considering the interaction volume of the E-beam in the phosphor.

In the FESEM the E-beam dwells for a short time $\Delta t$ on the $\mathrm{Y}_{2} \mathrm{O}_{3}: \mathrm{Eu}^{3+}$ nanoparticles having a diameter of $225 \mathrm{~nm}$, which corresponds to a cross section of $4 \times 10^{-10} \mathrm{~cm}^{2}$. In other words, the effective current density hitting the particle is $2.5 \mathrm{~A} / \mathrm{cm}^{2}$. The interaction volume of a narrow electron beam of $10 \mathrm{keV}$ impinging on a nanoparticle of $225 \mathrm{~nm}$ is depicted in Figure 13. This shows a simulation result generated with the Casino software package, made and described by Drouin et al. ${ }^{28}$ This package yields electron trajectories in a solid by a Monte Carlo algorithm. The essential output shown in Figure 13 is the interaction volume in a large crystal of $\mathrm{Y}_{2} \mathrm{O}_{3}$, much larger than the dimension of one spherical nanoparticle of $225 \mathrm{~nm}$. The effect of the denser $\mathrm{Eu}^{3+}$ may be neglected in these simulations. The cross section of the interaction volume is taken at the contour line of $95 \%$ absorbed energy. This interaction volume is much larger than the volume of one nanoparticle: therefore, a substantial fraction of the E-beam energy is

Table IV. Time constants of individual $\mathrm{Y}_{2} \mathrm{O}_{3}: \mathrm{Eu}^{3+}$ nanoparticles evaluated by ImageJ from CL-micrographs.

Concentration $\mathrm{Eu}^{3+}(\%)$ $\tau(\mathrm{ms})$

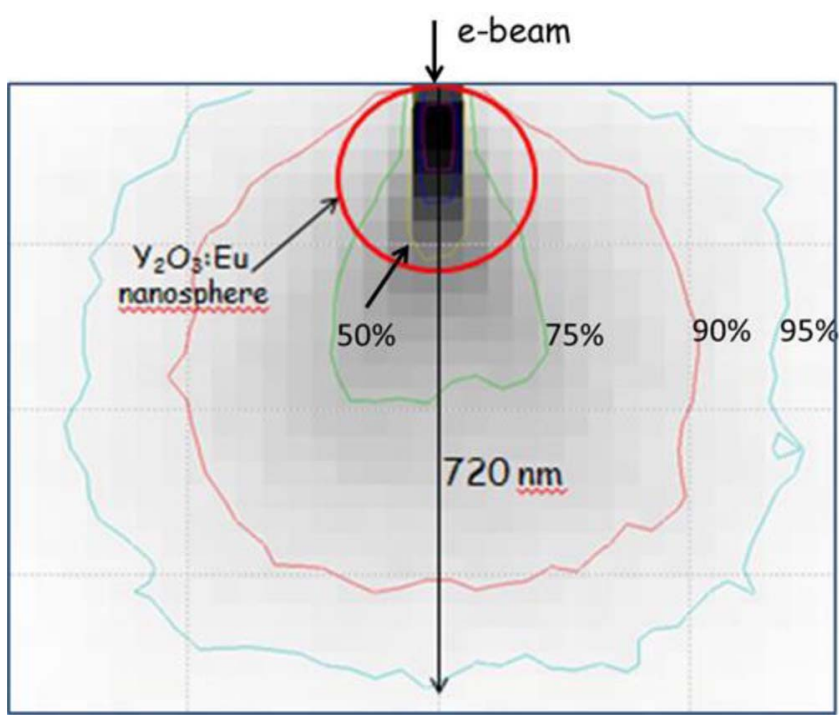

Figure 13. Casino simulation of electron trajectories in $\mathrm{Y}_{2} \mathrm{O}_{3}: \mathrm{Eu}^{3+}$. E-beam energy $10 \mathrm{keV}$. The volumes inside the contour lines have absorbed the indicated irradiated electron energy. The dimension of the nanospheres used in this work has been overlaid in the diagram to facilitate comparison.

not absorbed by the $\mathrm{Y}_{2} \mathrm{O}_{3}: \mathrm{Eu}^{3+}$ nanoparticle at $10 \mathrm{keV}$. The contour line of 50\% absorption is just within the dimensions of the nanoparticles used in this work, and thus slightly more than $50 \%$ of the electron energy is expected to be absorbed in the nanoparticle, if it were struck centrally (as shown) and less if it were struck to one side. From this consideration it can be concluded that the effective current density for the $\mathrm{Y}_{2} \mathrm{O}_{3}: \mathrm{Eu}^{3+}$ nanoparticles in the FESEM is approximately $0.5 \times 2.5$ $=1.25 \mathrm{~A} / \mathrm{cm}^{2}$ : this is still more than 6 orders of magnitude larger than the current density in the experiments described in the section on luminous efficiency and emission decay.

Klaassen et al. ${ }^{8}$ measured the CL saturation of transitions from the ${ }^{5} \mathrm{D}_{0}\left(\mathrm{C}_{2}\right)$ and ${ }^{5} \mathrm{D}_{1}\left(\mathrm{C}_{2}\right)$ levels for $\mathrm{Y}_{2} \mathrm{O}_{3}: \mathrm{Eu}^{3+}$ with $1 \% \mathrm{Eu}^{3+}$ as a function of current density between $1 \times 10^{-6}$ and $1 \times 10^{-2} \mathrm{~A} / \mathrm{cm}^{2}$ under stationary conditions. Figure 14 is a double log plot of the relative efficiencies of the dominant ${ }^{5} \mathrm{D}_{0}-{ }^{7} \mathrm{~F}_{2}\left(\mathrm{C}_{2}\right)$ transition at $611 \mathrm{~nm}$ and the fast decaying ${ }^{5} \mathrm{D}_{1} \rightarrow{ }^{7} \mathrm{~F}_{1}\left(\mathrm{C}_{2}\right)$ transition at $533 \mathrm{~nm}$ for $\mathrm{Y}_{2} \mathrm{O}_{3}: \mathrm{Eu}^{3+}$ with a Eu ${ }^{3+}$ concentration of $1 \%$, according to Klaassen et al. ${ }^{8}$ The curves at $\mathrm{j}>1 \times 10^{-2} \mathrm{~A} / \mathrm{cm}^{2}$ are extrapolations from the data of Klaassen et al. Point $\mathrm{F}$ in the plot indicates the effective current density for

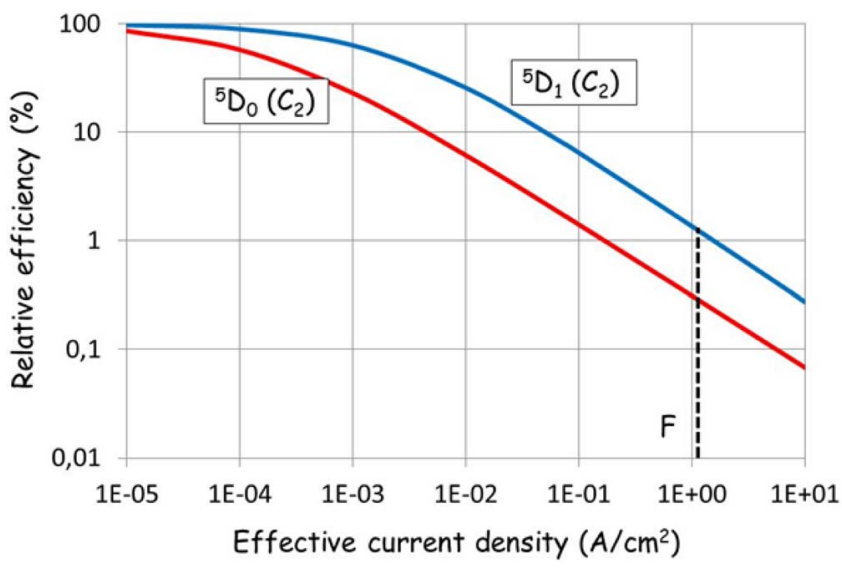

Figure 14. Relative CL-efficiency of two transition types in $\mathrm{Y}_{2} \mathrm{O}_{3}: \mathrm{Eu}^{3+}(1 \%$ $\mathrm{Eu}^{3+)}$ versus current density under stationary excitation conditions according to Klaassen et al. ${ }^{8}$ Point $\mathrm{F}$ on the horizontal axis marks the effective current density in the FESEM for one particle; it is located outside the measuring range of Klaassen et al. 
one $\mathrm{Y}_{2} \mathrm{O}_{3}: \mathrm{Eu}^{3+}$ nanoparticle in the FESEM. It can be seen that under stationary conditions the efficiency of the ${ }^{5} \mathrm{D}_{0} \rightarrow{ }^{7} \mathrm{~F}_{2}\left(\mathrm{C}_{2}\right)$ peak is only $0.3 \%$ of the efficiency at low current density $\left(1 \mu \mathrm{A} / \mathrm{cm}^{2}\right)$, while the efficiency of the ${ }^{5} \mathrm{D}_{1} \rightarrow{ }^{7} \mathrm{~F}_{1}\left(\mathrm{C}_{2}\right)$ transition is still $1.2 \%$ of its value at $1 \mu \mathrm{A} / \mathrm{cm}^{2}$.

Klaassen et al. ${ }^{8}$ also measured the current density $\mathrm{j}_{50 \%}$ at which the relative efficiency is 0.5 for various concentrations of $\mathrm{Eu}^{3+}$. At stationary conditions they found that $\mathrm{j}_{50 \%}$ varied only by a factor of 2 for a concentration change of a factor of 20 . In other words, $j_{50 \%}$ is rather insensitive to the $\mathrm{Eu}^{3+}$ concentration. Stationary conditions are defined by the inequality $\Delta \mathrm{t} / \tau>1$ : this holds for the ${ }^{5} \mathrm{D}_{1} \rightarrow{ }^{7} \mathrm{~F}_{1}\left(\mathrm{C}_{2}\right)$ transition at $533 \mathrm{~nm}$ with $\tau \approx 50 \mu \mathrm{s}$ in the normal scanning conditions of the FESEM, whereas we have $\Delta t / \tau<1$ for the ${ }^{5} D_{0} \rightarrow{ }^{7} F_{2}\left(C_{2}\right)$ transition at $611 \mathrm{~nm}$. Thus the application of the Klaassen et al. data for our FESEM experiments is not completely justified for the 611 $\mathrm{nm}$ transition. Nevertheless, it is assumed that the relative efficiency of this transition in the FESEM at $\Delta \mathrm{t}=260 \mu \mathrm{s}$ is only a little bit larger than under stationary conditions as represented in Figure 14.

In spite of this uncertainty, it can be concluded that Figure 14 provides a satisfactory explanation of the CL-micrographs in Figure 12: at low $\mathrm{Eu}^{3+}$ concentrations the light output for the ${ }^{5} \mathrm{D}_{0}-{ }^{7} \mathrm{~F}_{2}\left(\mathrm{C}_{2}\right)$ transition virtually disappears, whereas the fast decaying ${ }^{5} \mathrm{D}_{1} \rightarrow{ }^{7} \mathrm{~F}_{1}\left(\mathrm{C}_{2}\right)$ transition is still emitting light. The consequence is that the horizontal tails in Figure 12 disappear at low $\mathrm{Eu}^{3+}$ concentration, because the (very short) decay tail of the ${ }^{5} \mathrm{D}_{1} \rightarrow{ }^{7} \mathrm{~F}_{1}\left(\mathrm{C}_{2}\right)$ transition is hidden by the halo effect around the particles. It should be kept in mind that Figure 14 refers to relative efficiency, whereas Figure 12 refers to a greyscale being proportional to the total light output. Figure 14 also explains the decrease of the decay time of $\mathrm{Y}_{2} \mathrm{O}_{3}: \mathrm{Eu}^{3+}$ for low $\mathrm{Eu}^{3+}$ concentrations in Table IV, because the contribution of the ${ }^{5} \mathrm{D}_{0}$ levels in the decay phenomenon is almost disappearing, so that the effect of fast decaying ${ }^{5} \mathrm{D}_{\mathrm{J}}$ levels becomes clearer. As mentioned in the experimental section, the CL-detector in the FESEM was panchromatic; so, we could not record spectra of individual $\mathrm{Y}_{2} \mathrm{O}_{3}: \mathrm{Eu}^{3+}$ nanoparticles at high current density. We plan to do this in the future.

\section{Conclusions}

The results obtained in this CL study of monosized spherical nanoparticles $\mathrm{Y}_{2} \mathrm{O}_{3}: \mathrm{Eu}^{3+}$ largely confirm the work on micrometer sized $\mathrm{Y}_{2} \mathrm{O}_{3}: \mathrm{Eu}^{3+}$ published between 1970 and 1995 .

One clear difference is the luminous efficiency, which is about $30 \%$ lower for the nanoparticles than that of micrometer sized particles.

We have presented a new theory that enables a straightforward evaluation of the critical distance for radiationless energy flow from $\mathrm{Eu}^{3+}$ ions in $\mathrm{S}_{6}$ sites to $\mathrm{Eu}^{3+}$ ions in $\mathrm{C}_{2}$ sites. This evaluation requires recording of CL spectra at various $\mathrm{Eu}^{3+}$ concentrations at room temperature.

From the explanation of the results we have discussed above we find no evidence for a none statistical preference of $\mathrm{Eu}^{3+}$ for either of the crystallographic sites in cubic $\mathrm{Y}_{2} \mathrm{O}_{3}: \mathrm{Eu}^{3+}$.

From the detailed analysis of the decay of the ${ }^{5} \mathrm{D}_{0} \rightarrow{ }^{7} \mathrm{~F}_{2}\left(\mathrm{C}_{2}\right)$ transition at $611 \mathrm{~nm}$ and ${ }^{5} \mathrm{D}_{0} \rightarrow{ }^{7} \mathrm{~F}_{1}\left(\mathrm{~S}_{6}\right)$ transition at $582 \mathrm{~nm}$ it was found that the interaction between excited $\mathrm{Eu}^{3+}$ ions varies with the inverse of the sixth power of the $\mathrm{Eu}^{3+}: \mathrm{Eu}^{3+}$ distance indicating that this type of interaction has a dipole-dipole nature.
Furthermore, we have shown that the interpretation of FESEM CL-micrographs of $\mathrm{Y}_{2} \mathrm{O}_{3}: \mathrm{Eu}^{3+}$ nanoparticles was possible due to the detailed information that was published on the saturation and decay behavior. Conversely it can be concluded that CL-microscopy offers opportunities to generate new information on (nanostructured) phosphors.

\section{Acknowledgments}

We are grateful to the EPSRC and Technology Strategy Board (TSB) for funding the PURPOSE (TP11/MFE/6/1/AA129F; EPSRC TS/G000271/1) and CONVERTED (JeS no. TS/1003053/1) and FAB3D programs. We are also grateful to the TSB for funding the CONVERT program.

\section{References}

1. D. den Engelsen, P. G. Harris, T. G. Ireland, R. Withnall, and J. Silver, ECS J. Solid State Sci. Technol., 2, R201 (2013).

2. D. den Engelsen, P. G. Harris, T. G. Ireland, and J. Silver, ECS J. Solid State Sci. Technol., 3, R53 (2014).

3. P. Harris, D. den Engelsen, T. Ireland, G. Fern, and J. Silver, Proceedings of ICOOPMA (2014)

4. J. Heber, K. H. Hellwege, U. Köbler, and H. Murmann, Z. Physik, 237, 189 (1970)

5. R. G. Pappalardo and R.B. Hunt, J. Electrochem. Soc., 132, 721 (1985)

6. R. B. Hunt and R. G. Pappalardo, J. Lumin., 34, 133 (1985).

7. M. Buijs, A. Meyerink, and G. Blasse, J. Lumin., 37, 9 (1987).

8. D. B. M. Klaassen, R. A. M. van Ham, and T. G. M. van Rijn, J. Lumin., 43, 261 (1989).

9. D. B. M. Klaassen, T. G. M. van Rijn, and A. T. Vink, J. Electrochem. Soc., 136, 2732 (1989).

10. H. Bechtel, W. Czarnojan, M. Haase, W. Mayr, and H. Nikol, Philips. J. Res., 50, 433 (1996).

11. S. Yang, J. A. Cooper, C. Stoffers, F. Zhang, J. Penczek, B.K. Wagner, S. M. Jacobsen, and C. J. Summers, Extended abstracts of the second international conference on the science and technology of display phosphors, November 18-29, San Diego, CA, 255 (1996).

12. K. Ohno in "Phosphor Handbook", Chapter 6, Edited by W. Yen, S. Shionoya, and H. Yamamoto, 2nd ed., CRC-Press, Boca Raton (2007).

13. X. Jing, T. Ireland, C. Gibbons, D. Barber, J. Silver, A. Vecht, G. Fern, P. Trogwa, and D. Morton, J. Electrochem. Soc., 146, 4654 (1999).

14. Y. D. Jiang, Z. L. Wang, F. Zhang, H.G. Paris, and C. J. Summers, J. Mater. Res., 13, 2950 (1998).

15. S. Ray, P. Pramanik, A. Singha, and A. Roy, J. Appl. Phys., 97, 094312 (2005).

16. G. Jia, M. Yang, Y. Song, H. You, and H. Zhang, Cryst. Growth Des., 9, 301 (2009)

17. Y. Chung, S. Park, K. Jang, I. Kim, Y. I. Lee, and H. J. Seo, J. Korean Phys. Soc., 42, 543 (2003).

18. M. I. Martinez-Rubio, T. G. Ireland, G. R. Fern, J. Silver, and M. J. Snowden, Langmuir, 17, 7145 (2001)

19. P. A. Tanner, L. Fu, and B-M. Cheng, J. Phys. Chem. C, 113, 10773 (2009).

20. E. Antic-Fidancev, J. Hölsä, and M. Lastusaari, J. Phys.: Condens. Matter, 15, 863 (2003).

21. J. Silver and R. Withnall, Chem. Rev. 104, 2833 (2004).

22. G. Schaack and J. A. Koningstein, J. Opt. Soc. Am., 60, 1110 (1970).

23. J. Silver, T. G. Ireland, and R. Withnall, J. Electrochem. Soc., 151, H66 (2004).

24. J. B. Talbot, E. Slusky, and S.K. Kurinec, J. Mater. Sci., 39, 771 (2004).

25. S. Qiang, C. Barthou, J. P. Denis, F. Pelle, and B. Blanzat, J. Lumin., 28, 1 (1983)

26. J. Thomes, C. Seager, D. Tallant, and P. Holloway, Extended abstracts of the sixth international conference on the science and technology of display phosphors, November 6-8, San Diego, CA, 249 (2000).

27. C. H. Seager, D. R. Tallant, M. Hampden-Smith, and D. Skamser, Extended abstracts of the fifth International conference on the science and technology of display phosphors, November 8-10, San Diego, CA, 321 (1999).

28. D. Drouin, A. R. Couture, D. Joly, X. Tastet, V. Aimez, and R. Gauvin, Scanning, 29, 92 (2007) 